\title{
Work Standardisation in Logistics Processes
}

\author{
DOI: 10.12776/QIP.V21I2.880
}

\author{
Martina Džubáková, Michal Kopták
}

Received: 23 February 2017 Accepted: 07 May $2017 \quad$ Published: 31 July 2017

\begin{abstract}
Purpose: The article presents a concept of synergy between MTM (Methods Time Measurement) and TWI (Training within the Industry) methods through a case study conducted on elementary logistics processes. MTM brings optimisation into logistics operations and creates quality and efficiency standards. TWI provides the means of application of these standards at work to drive improvement.
\end{abstract}

Methodology/Approach: To show a prospective viability/added value of the MTM and TWI combination, we present a case study involving simple logistics processes. We use the MTM as a standardisation method and the TWI as a variability control and process improvement concept.

Findings: The MTM times generally determined as an external regulation, may not reflect the level of skills of workers in a specific company and often create a barrier to internal improvement. The concept of work standardisation based on the MTM method synergised with the TWI creates a dynamic improving system.

Research Limitation/implication: Individual variations in the processes need to be accounted for and the terminology of current optimisation method and improvement concept need to be adapted accordingly in the present analysis. The methods of MTM and TWI employed in our study now slowly penetrate the logistics processes.

Originality/Value of paper: The paper introduces a new approach to the methodology of internal logistics improvement. The MTM work standards increase the stability and productivity in logistics. However, they often hinder the change by allowing for only low degree of flexibility. Combining them with the concept of TWI, we can enhance quality and foster the human potential to change.

Category: Case study 
Keywords: MTM; MTM-logistics; TWI - training within the industry; Kaizen

\section{INTRODUCTION}

Work standardisation is not a new concept. It has been a key factor for industrial evolution since Taylor's times. Frederik Taylor introduced the idea of Time Studies by observing a job and breaking it down into individual tasks (Taylor, 1967). Work standards enabled a worker to work faster while achieving better quality. Many scientific studies followed with further development of work standardisation and predetermined motion time systems (PMTS). PMTS are work measurement systems based on the analysis of work into basic human motions, classified according to the nature of each motion and the conditions under which the motion is made (Mital, Desai and Mital, 2017). The first PMTS foundation was laid out by the research and development of Frank B. and Lillian M. Gilbreth (Gilbreth, 1912). One of the significant advantages of PMTS is that they require a detailed description of the working method, and are thus useful for studying how work is done, how it can be improved and how much time it should take (Khanna, 2017). In the 1950s Maynard, Stegemerten and Schwab (1948) developed Methods Time Measurement (MTM). The MTM was the first of a series of predetermined motion time systems, predetermined in the sense that estimates of time are not determined in individually, but are derived from an industry standard. The MTM methods are nowadays used in most countries in various industries. This is due to their use in the planning stages and further translated into a standardised performance level (Bures and Pivodova, 2015). The MTM facilitates performance rating and eliminates subjective aspects. It can be used in the planning stages, it offers common work standards in industry, etc. (Chary, 2009). Worker cooperation and compliance are not required, and the workplace is not disrupted. Performance ratings are included in the motion times, eliminating this subjective part of developing standard times.

Development of logistics is driven by the development of the economy and by increasing demands placed on quality and quantity of production and service processes. Logistics services represent the source of competitiveness and enter a competitive relationship within the whole supply chain. Logistics management is part of the supply chain management that plans, implements, and controls the efficient and effective, forward and reverse flow and storage of goods, services and related information between the point of origin and the point of consumption, to meet customers' requirements (Council of Supply Chain Management Professionals Definitions and Glossary). Trying to understand and meet customer's requirements of quality and price, the companies are forced to find new options how to make profitability sustainable. Therefore, it is necessary to be aware how to improve logistics processes. Internal logistics utilises labour and machine work by the use of technology at different levels of mechanisation and automatization (for example material loading and unloading, transportation, warehousing, unit supply, removal of finished products or component sub- 
assemblies). Quality and efficiency of logistics deeply depend on stability and capability of logistics processes. One of the most significant criteria for stability and capability control in logistics is TIME. Logistics processes and operations shall be controlled within the scope of acceptable variability by sustainable flexibility.

\section{METHODOLOGY}

The presented case study shows the prospectiveness of the MTM (Methods Time Measurement) and the TWI (Training within the Industry) combination in logistics processes. According to Yin, a case study is an effective strategy for exploring "HOW" or "WHY" questions (Yin, 2009). In this research, we establish "HOW" and "WHY" the MTM and the TWI methods can be combined. We use the MTM as an effective standardisation method and the TWI as a variability control and process improvement concept. Our assumption was that the MTM brings optimisation into logistics operations to create the quality and efficiency standard in individual activities and that the TWI provides a way of applying that standard to work to enhance the improvement cycle.

The MTM is one of the major PMTS (Predetermined motion time systems) system, which is actually a group of MTMs operating at different levels and applicable to different types of work. MTM1 is the most detailed level of the family, developed by analysing large numbers of repetitive cycles of manual work (Delmar and Franklin, 1987). MTM1 (basic motion time up 0.5 min) gives values for basic hand or arm motions (reach, move, turn, grasp, position, disengage and release) and set of full body motions. For example, the time taken to "REACH TO" an object is then given by a table based on the kind of "REACH" (the object position) and the distance "TO BE REACHED". MTM1 is suitable for measuring short cycle, highly repetitive work. Users can take advantage of this method, for example short preparation time and international acceptance of predetermined time standards (Szombathyova and Šebo, 2006). Other "members" of the MTM group use description of lower level motions. MTM2 is more suited for longer cycle work when the fine level of decomposition of MTM1 is unnecessary in terms of meeting accuracy requirements. It is usually achieved by combining, statistically averaging, substituting or eliminating certain basic motions (Salvendy, 2001). Apart from the basic motions, MTM2 also consists of motions such as "GET" and "PUT".

MTM3 then uses very low description motions such as "HANDLE". A higher level, such as MTM5, consists of a combination of simple and complex elements. The MTM has a growing importance in the area of internal logistics. The main reason is the need to increase the efficiency and quality of logistics as generally "non-valuated" activities. The evolution of time standardisation in logistics has focused on qualified estimates or empirical data based on history up to the more exact ones - time studies using direct measurement or using a method of predetermined times (Klaus, 2009). Since the founding of the MTM Association, 
there has been a long tradition of using the MTM and applying the same to logistics. An MTM data catalogue for transport and storage was established at the request of members of the association already in 1970. In 2003, those data were completely revised and edited to comply with newly adopted strict logistics requirements (Beňo, Hrdinová and Sakál, 2013).

The TWI is an industrial training program used in the USA since WWII, also called the $3 \mathrm{~J}$ program. It has three specific "J" components: Job Instruction (JI), Job Methods (JM), and Job Relations (JR). The program is focused on tree core skills: How to train people to do the job correctly (JI). How to improve the way jobs are done (JM). How to handle and prevent relation problems (JR) (Allen, 1919).

After Japan's defeat, the TWI was incorporated into the Japanese country reconstruction program (War Manpower Commission, 1945) and over the following decades, it became an integral part of what is known today as the Japanese Management. Toyota adopted Training within Industry program, and the Job instruction method is mirrored in the principles of Toyota Production System as "Standardised Work". The famous Japanese method of Kaizen (continuous improvement) is based on the second J program - Job method. From the post-war-Japan until nowadays, Kaizen has become one of the most successful management techniques in the world.

Currently, we are witnessing the TWI rebirth since Training within Industry: The Foundation of Lean by Donald Dinero came out in 2005 (Dinero, 2005), followed by Conrad Soltero's book The 7 Kata: Toyota Kata, TWI, and Lean Training in 2012, the famous Mike Rothers's book Toyota Kata in 2009 and other. The rebirth is occurring primarily in the "Lean" community. Many companies are working to be lean, but most fail to achieve Toyota's level of success (Liker, 2004). The answer is the absence of "honest" $3 \mathrm{~J}$ approach, as the primordial part of TPM (Toyota production system, nowadays known as "Lean Manufacturing"). TWI provided Toyota with some key skills over those "Leanseeking" companies that simplify the TPM into the LEAN toolkit without the basic system sense. Lean loses its impact over time and people do not sustain the changes.

\section{WORK STANDARDIZATION AND STABILITY IN LOGISTICS}

Work standardisation is the main premise for achieving an accurate quality result. Work standard is a term designating a sequence of steps by which identical results can be achieved regarding time, procedure/work technique, product and quality. A certain sequence of steps and rules is accepted by all a new and an old employee alike. The standard becomes a natural part of the process and all abnormalities can be easily identified. Standardisation is an essential part of a viable production (Gopalakrishnan, 2010). Similar processes (working methods) with high duplication occur in logistics in a variety of business areas. Processes 
(working methods), of different complexity, are known as standard working methods. The MTM logistics applies to standard processes lasting between 3 and 30 minutes, decomposes them, describes them, assigns rules to them, defines the quantity and finally determines table-based time standards.

The time duration of a manual logistics activity (e.g. repackaging of any material, opening and closing a cardboard cover, labelling, etc.) is determined by an MTM-UAS (Universal Analysing System) system for processes $0.5 \mathrm{~min}-3 \mathrm{~min}$. Coding of every single process runs through data card system, which contains a predefined range of activities and operations with relevant allocation code and time value measured in timer units TMU ( $1 \mathrm{TMU}=0.036 \mathrm{~s}=0.0006 \mathrm{~min})$. An example of the data card is shown in Tab. 1.

Table 1 - Example of Coding in MTM-LOGISTICS

\begin{tabular}{|c|c|c|c|}
\hline \multicolumn{2}{|c|}{ Procedural steps for transport - general features } & Code & TMU \\
\cline { 3 - 3 } & 4LT & \\
\hline \multirow{2}{*}{ Control } & Steering lever & ABH & 18 \\
\cline { 2 - 3 } & Joystick & ABJ & 10 \\
\hline
\end{tabular}

The code for steering lever can be booked in the form $4 \mathrm{LTABH}$ with time value $18 \mathrm{TMU}$ $(0.648 \mathrm{~s})$

\subsection{Standardisation Case - Transport from Receiving Area to Shelves}

Time analysis was done in a warehouse run by the Logistics Planning Department. There was a need to analyse 25 repeating processes. Due to lack of space, we shall describe only one warehouse sub-process, with standards given for time reduction and optimisation. We have chosen one of the standard operations that occurs in almost any warehouses.

Before proceeding with an analysis, there was a need to check time listed in actual internal documents. Transport from receiving area requires completion of 4 task:

- Pallet discharge.

- Transport of fully loaded pallet from receiving area to shelves.

- Transport of unloaded pallet in circulation.

Time listed in internal documents for this process was $2.52 \mathrm{~min}$. In spite of the fact that we received data from the company, as well as observed the process in motion, we had to conduct our own time studies to get exact information on the cycle times within the warehouse. The average time after 25 measurements were 2.85 min (Fig. 1).

We analysed the process with real time value, which is in average $0.33 \mathrm{~min}$ greater than the time listed in internal documents before primary measuring. The variability of the measured time directs our attention to deeper analysis of the 
process. The range of the process is $1.3 \mathrm{~min}$. That means, that current standards are lower than those calculated by the company.

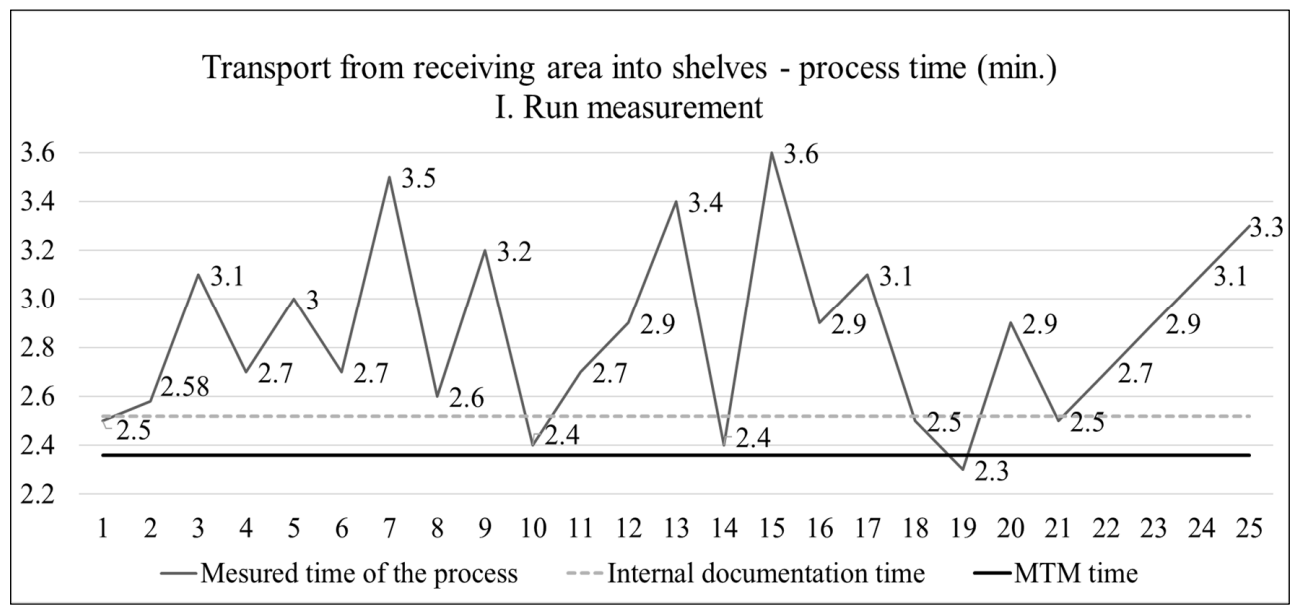

Figure 1 - Transport from Receiving Area into Shelves - Process Time (min)

Carrying out the analysis using the MTM-LOGISTICS method, we discovered more time space and that means a waste of time in individual process sequences (Fig. 2). Total savings of time compared to time presented by actual company standard can differ by $0.16 \mathrm{~min}$, compared to average real time of $0.49 \mathrm{~min}$. After analysing the reasons attributable to time variability, we arrived at the conclusion that the work standard is not implemented in the warehouse, and the work methods are not adjusted to the traffic situation on the warehouse floor. The required MTM time is $2.36 \mathrm{~min}$.

The MTM specifies internationally accepted time of elemental tasks in predicted workflow for a well-trained worker. The questions are:

- How to reach the MTM time as quickly as possible (how many work cycles does it take for a worker to reach the Time standard)?

- Is the MTM time most efficient according to the value of its outcomes and for processing customer needs? Is it possible to use the MTM and to accelerate the improvement cycle? 


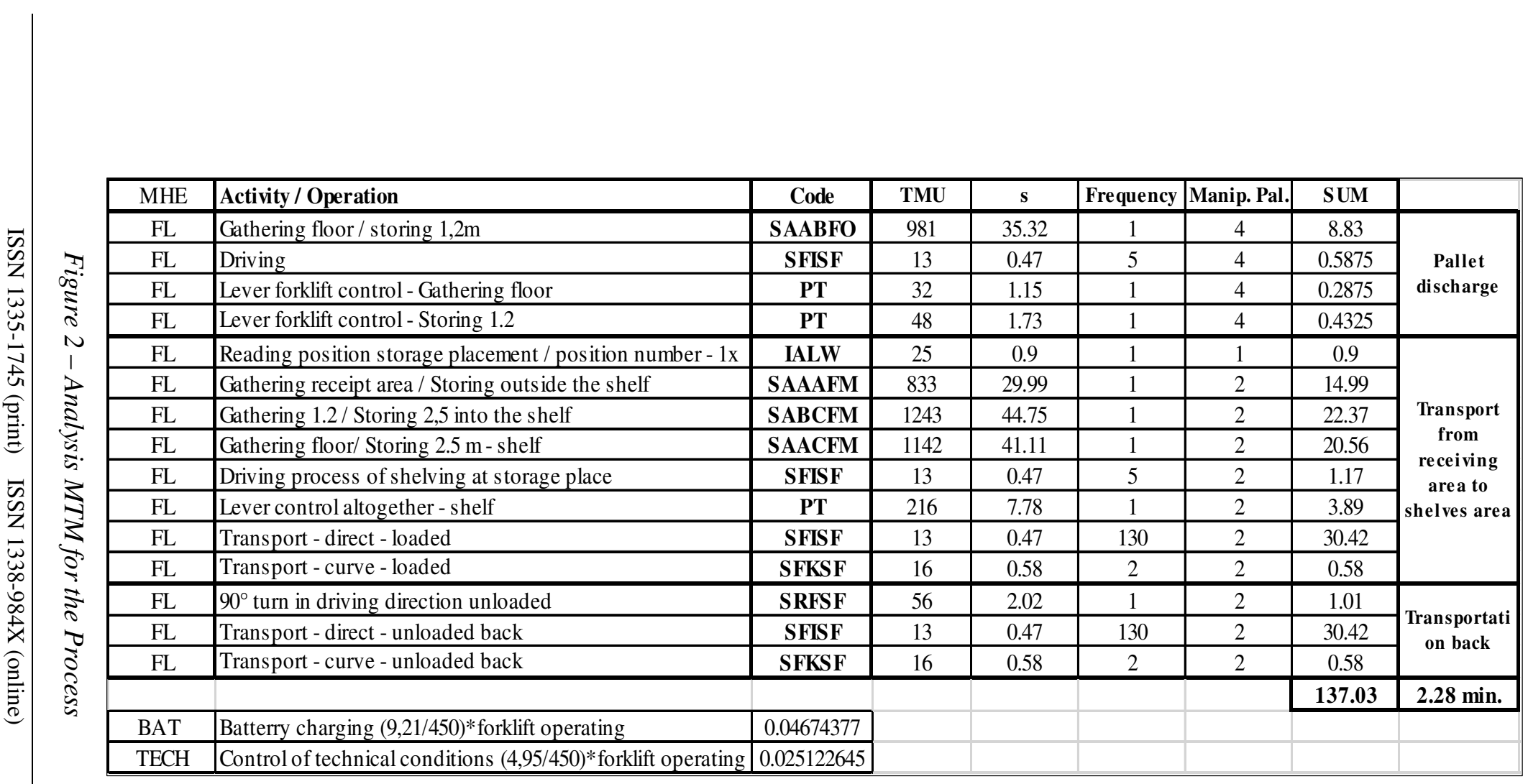


A work standard calculated by the MTM is usually an external input and it represents the optimum performance the operator shall be prepared to reach. The learning phase can last anywhere between a few weeks and a year, depending on several factors, such as a degree of automatization, task complexity, operators experience and qualification, etc. But usually one lesson is burnt deep in the operators' heads, when incentive earnings appear, steps are taken to find ways to tighten the time standards. On the other hand, when good conditions for organisational learning occur, they may help reach the standard faster, break mental models and later overcome the expected criteria by improvement actions from inside (Ezey, 2013).

\subsection{J Program to Achieve the MTM Time and Reduce Variability}

The traditional approach to job/work instruction (when engineering creates work standards and delivers job instructions to the manufacturing) shows several problems with implementation:

- Operators lack a deeper understanding of work instructions.

- Rarely can it be used as a problem-solving measure to eliminate waste from workplace/operation.

- Often it cannot fully reflect real situation on the line.

- It is slow, or not updated when change is made.

- There is only a weak motivation for internal improvement measures.

These problems are often the cause of a process instability and for that matter also process incapability. Basic stability of the process starts with the work standardisation and well-trained workforce. Stability is generated by doing the same thing the same way across operators and shifts. The importance of "training and instructing" instead of "telling" is the main concept of the TWI first "J program", Job Instruction. Job instruction is the program how to instruct a worker to perform a job correctly, safely and conscientiously (Huntzinger, 2006).

Processes are performed by various workers using different methods with different results, as in the Warehouse case. The Job Instruction requires identification of the best working standard for the process, training an employee to attain it, creating standardised work thereby. We use the MTM analysis result and work decomposition and create a work instruction (Fig. 3). The working standard was developed as the Job Breakdown through a description of:

- Important Steps (WHAT?) of the process - Pallet load, Transport of loaded pallet form receiving area to shelves, Transport back to the receiving area.

- Key Points for each step (HOW?) - might make or break the work, important to avoid injury, errors, make the work easier. 
- Determination of reasons for the key points (WHY?).

Figure 4 shows the experience of time measurement of the transport process from receiving area into shelves after the first JI training following the 4 - steps training methodology: 1. Prepare the worker. 2. Present the operation according to Job breakdown. 3. Try worker outperformance. 4. Follow-up.

Proper working instruction eliminated variability and reduced average time from 2.85 to $2.64 \mathrm{~min}$. Residual variability is caused by traffic situation in the warehouse. Forklift drivers often must stop and yield to other vehicles. After first "J", a variability reduction of $0.22 \mathrm{~min}$ was achieved.

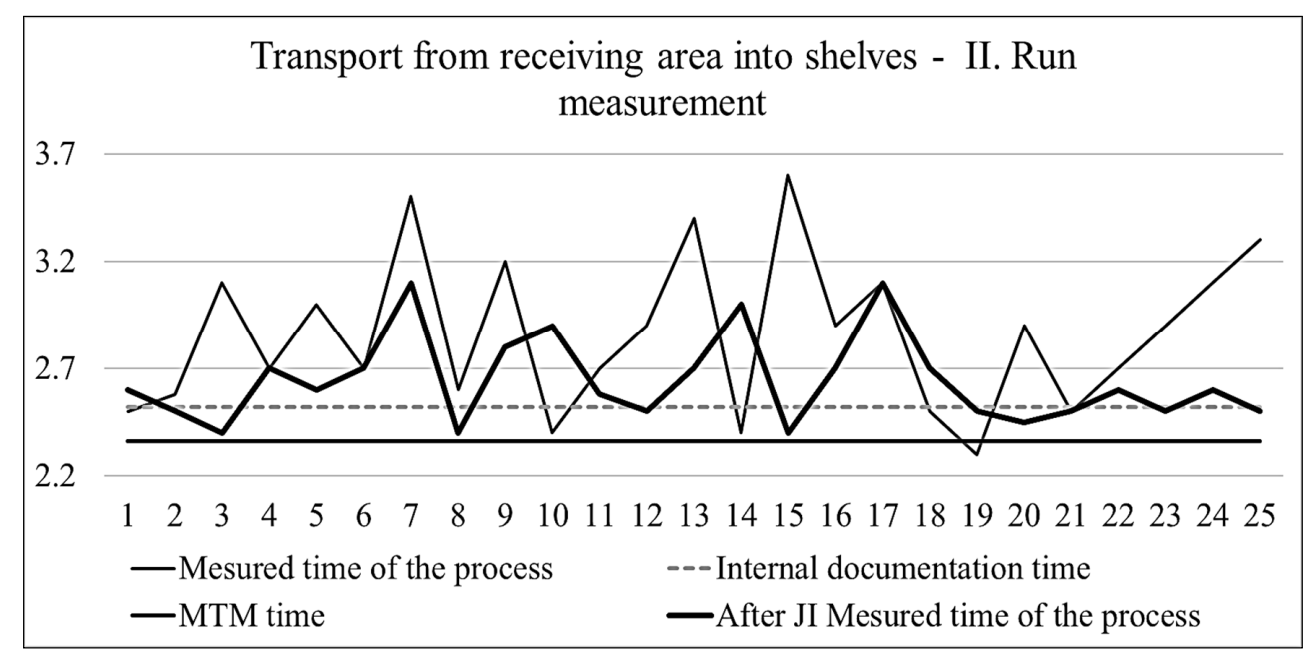

Figure 3 - Transport from Receiving Area into Shelves - Process Time (min) II. Run Measurement

Job Methods (JM) is the next TWI program (not applied in the study, but shall be developed to accelerate internal improvements). There is a real prospect of avoiding logistics MUDA in the warehouse with application of JM and of achieving the MTM standard time thanks continuous improvement.

Job Method evolved into KAIZEN - a Continuous Improvement concept, known as high volume of small incremental improvements from individuals. It is based on the Job Instruction experience conditioned by Standardised work. After proper training (training by doing) and deep experience with the process, JM helps individuals to break down the job to its details and to eliminate wasteful tasks, to combine and rearrange necessary tasks and to simplify those tasks that are required (Huntzinger, 2002). 


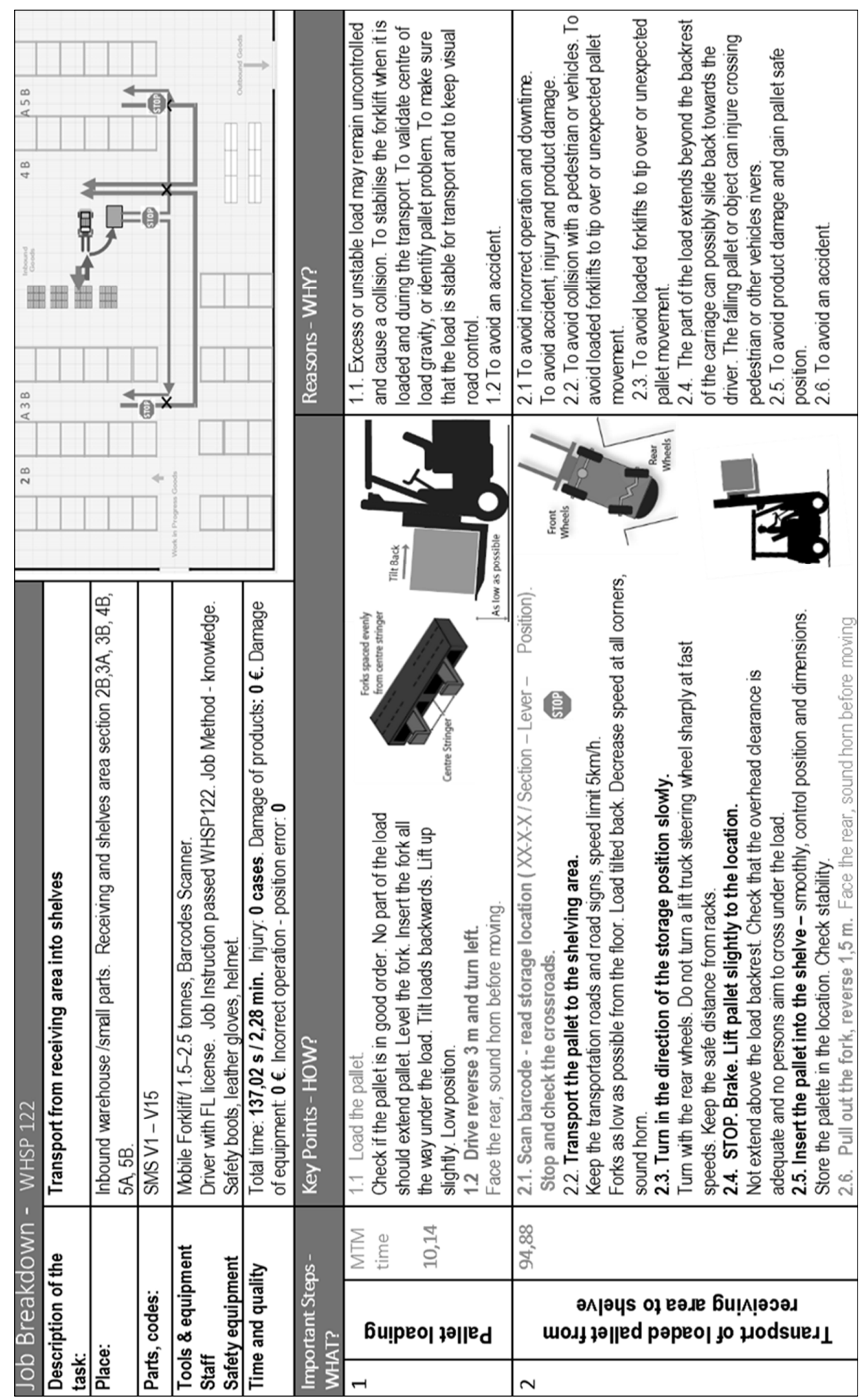

Figure 4 - Job Breakdown - Job Instruction 


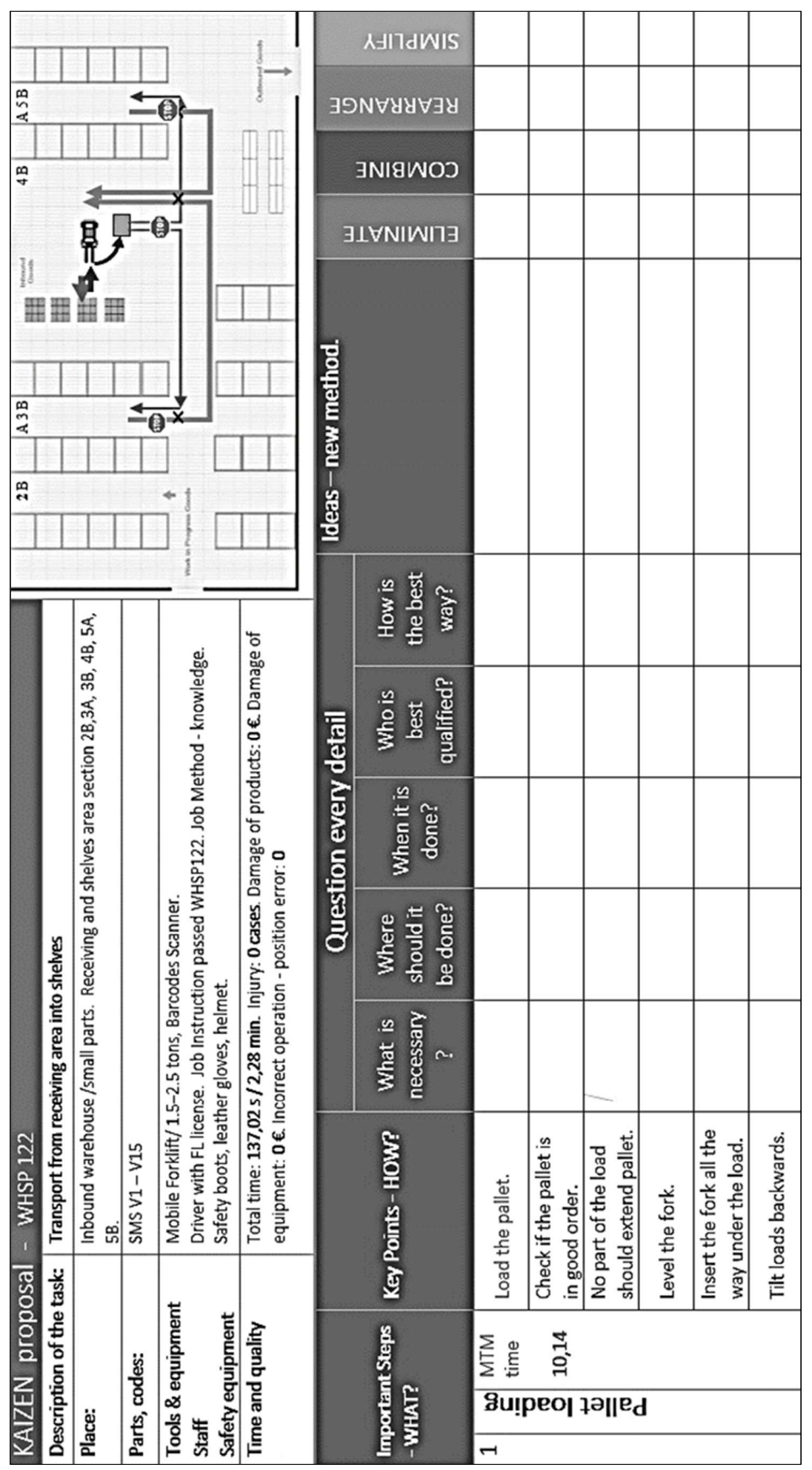

Figure 5-Job Method Example 
JM involves 4 steps: 1. Job Breakdown (we used breakdown experience from JI). 2. Question all important aspects. 3. Develop the new method (eliminate the unnecessary, combine process parts, rearrange for better sequence, simplify and straighten process). By following the four-step Job Methods procedure, we can discover improvements based on workers' experience. An outline of the procedure was printed and given to the trainees (the template of the Job Methods form is shown in Fig. 5).

A similarity to KAIZEN can be seen in the phrases commonly used in eliminating waste and making work task improvements to perpetually drive improvement activities. The answers to "What?" identify unnecessary details to be eliminated. "Where? When? and Who?" give proposals for combining and rearranging. The answers to "How?" provide leads for the best way to simplifying. Job Methods is transformed to the well-known 5W 1H method.

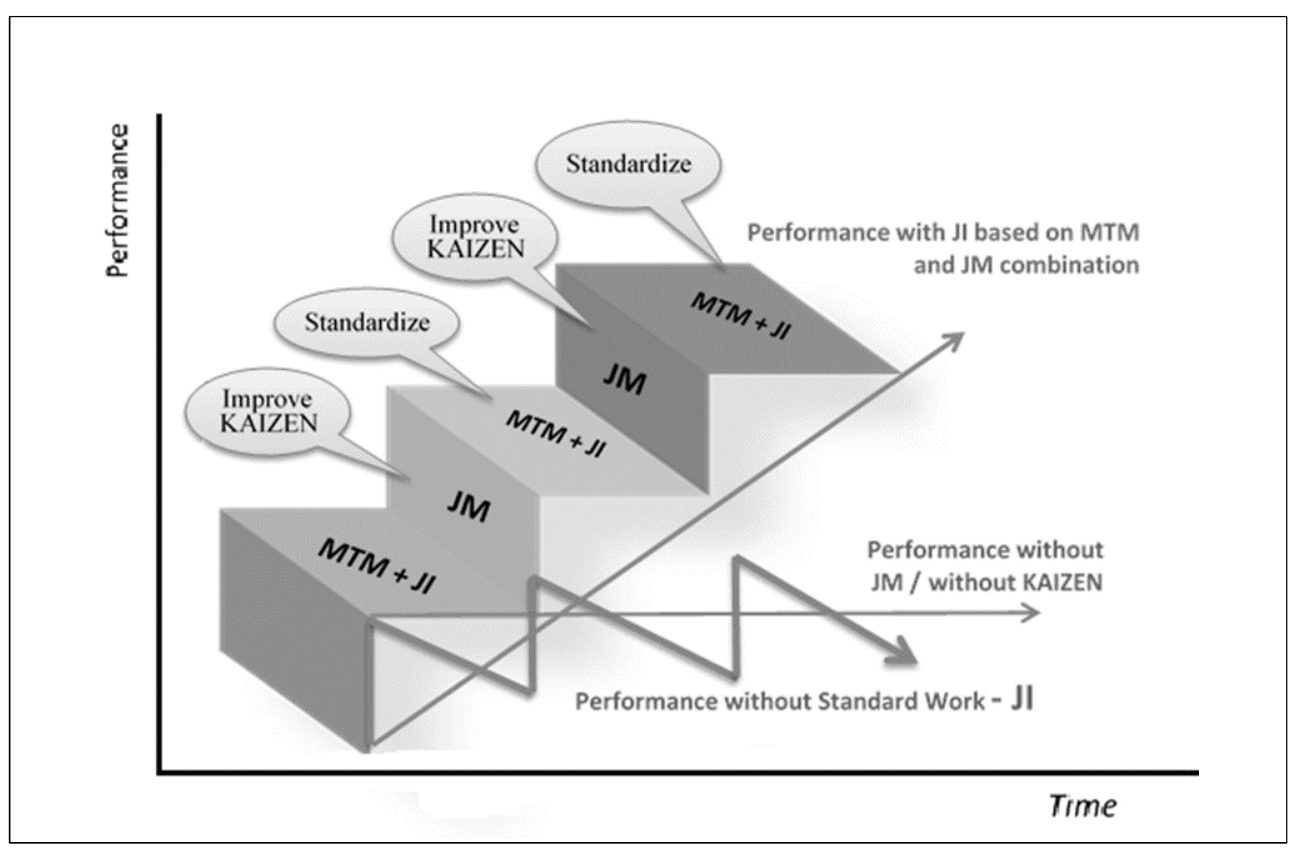

Figure 6 - JI and JM Combination Effect

Combining the JI based on the MTM job decomposition and the JM program a continuous improvement system can be developed. The MTM gives us internationally accepted basis for work standard and job instruction development. The JI helps to train the workers and provides them with a deep understanding of the work. After all JM opens the "Door" to accelerate Kaizen. 


\section{CONCLUSION}

The MTM, as one of the predetermined motion time systems, is nowadays used in most countries in various industries. The basic goal is to achieve higher quality and work efficiency. Computer supported MTM opened opportunities to run MTM permanently, reflecting process changes, greatly reducing application time and the time to optimise processes. However, the MTM is characterised by several disadvantages. Predetermined motion times are generally determined from a broad sample of workers across several industries, they may not reflect the skill level, training, or abilities of workers in a specific company. There is less personal contact with employees. Therefore, the MTM standard as an external regulation often creates barriers to internal improvement. On the other hand, people have to live with the standards and achieve them. Continuous improvement system can be created in synergy with the TWI. This article introduces the concept of work standardisation based on the MTM method where the improvement is achieved through application of the JI and JM methods respectively. The Job Instruction method helps to avoid variability and achieve the standard time faster. The JM accelerates the improvement cycle to avoid inefficiency and waste.

\section{REFERENCES}

Allen, E., 1919. The Instructor, the Man and the Job. Philadelphia and London: J.B. Lippincott Company.

Beňo, R., Hrdinová, G. and Sakál, P., 2013. MTM - Logistika efektívny nástroj pre analýzu materiálového toku. Transfer inovácií, 25/2013, pp.1-2.

Bures, M. and Pivodova, P., 2015. Comparison of Time Standardization Methods on the Basis of Real Experiment. Procedia Engineering, [e-journal] 100, pp.466 474. http://dx.doi.org/10.1016/j.proeng.2015.01.392.

Chary, S., 2009. Production and operations management. $4^{\text {th }}$ Ed. New Delhi: Tata McGraw-Hill Education Pvt. Ltd.

Delmar, W. and Franklin, H., 1987. Engineered Work Measurement: The Principles, Techniques, and Data of Methods-time Measurement Background and Foundations of Work Measurement and Methods-time Measurement. New York: Industrial Press.

Dinero, D., 2005. Training within Industry: The Foundation of Lean. Portland, OR: Productivity Press.

Ezey, M., 2013. Human Learning: From Learning Curves to Learning Organizations, International Series in Operations Research \& Management Science. New York: Springer Science \& Business Media.

Gilbreth, F., 1912. Primer of Scientific Management. New York: Kessinger Publishing. 
Gopalakrishnan, N., 2010. Simplified Lean Manufacture: Elements, Rules, Tools and Implementation. New Delhi: PHI Learning Private Limited.

Huntzinger, J., 2002. The Roots of Lean. Training within Industry: The Origin of Kaizen. Association for Manufacturing Excellence, [online] Available at: $<$ http://twihr.leanfrontiers.com/wp-content/uploads/2015/12/Roots-of-Lean-

TWI-Huntzinger-Target-2002.pdf $>$ [Accessed 10 October 2016].

Huntzinger, J., 2006. Why Standard Work is not standard: Training within Industry Provides an Answer. Association for Manufacturing Excellence, [online] Available at:

$<$ http://twinetwork.com/files/upload/articles/Why\%20Standard

$\% 20$ Work\%20is\%20not\%20Standard.pdf> [Accessed 10 October 2016].

Khanna, R.B, 2017. Production and Operations Management. $2^{\text {nd }}$ Ed. New Delhi: PHI Learning Pvt. Ltd.

Klaus, P., 2009. Logistics research: a 50 years' march of ideas. Logistics Research, [e-journal] 1(1), pp.53 - 65. http://dx.doi.org/10.1007/s12159-0080009-y.

Liker, J.K., 2004. The Toyota Way: 14 Management Principles from the World's Greatest Manufacturer. New York, NY: McGraw-Hill Professional.

Maynard, H., Stegemerten, G. and Schwab, J., 1948. Methods-time measurement. New York, NY: McGraw-Hill.

Mital, A., Desai, A. and Mital, A., 2017. Fundamentals of Work Measurement: What Every Engineer Should Know. New York, NY: Tailor \& Francis Group.

Salvendy, G., 2001. Handbook of Industrial Engineering: Technology and Operations Management. New York, NY: John Wiley \& Sons.

Szombathyová, E. and Šebo, J., 2006. Využitie metódy MTM pri racionalizácii pracovnej činnosti. Transfer inovácií, 9/2006, pp.200-202.

Taylor, F.W., 1967. The Principles of Scientific Management. New York, NY: Norton Library.

War Manpower Commission, 1945. The Training Within Industry Report, 19401945: A Record of the Development of Management Techniques for Improvement of Supervision, Their Use and the Results. Washington, DC: War Manpower Commission, Bureau of Training, Training within Industry Service.

Yin, R.K., 2009. Case study research. Design and methods. $4^{\text {th }}$ Ed. California: Thousand Oaks.

\section{ABOUT AUTHORS}

Ing. Martina Džubáková, PhD., Assistant Professor, University of Economics in Bratislava, Faculty of Business Management, Department of Production Management and Logistics Function, e-mail: martina.dzubakova@euba.sk. 
Ing. Michal Kopták, Internal Graduate Student, University of Economics in Bratislava, Faculty of Business Management, Department of Production Management and Logistics Function, e-mail: koptak.michal@gmail.com.

(C) 2017 by the authors. Submitted for possible open access publication under the terms and conditions of the Creative Commons Attribution (CC-BY) license (http://creativecommons.org/licenses/by/4.0/). 